\title{
A PERCEPÇÃO SOBRE O USO DA MADEIRA DE EUCALIPTO PELOS FABRICANTES DO POLO MOVELEIRO DE UBÁ-MG ${ }^{1}$
}

Tatiana de Oliveira Borges Teixeira ${ }^{2}$, Márcio Lopes da Silva ${ }^{3}$, Laércio Antônio Gonçalves Jacovine ${ }^{3}$, Sebastião Renato Valverde ${ }^{3}$, José de Castro Silva ${ }^{3}$ e Vanessa Aparecida Vieira Pires ${ }^{2}$

\begin{abstract}
RESUMO - Este trabalho analisou a percepção dos fabricantes do Polo Moveleiro de Ubá, MG, quanto à utilização da madeira de eucalipto para a fabricação de móveis. A crescente restrição ambiental ao uso de madeiras provenientes de florestas nativas tem estimulado a utilização da madeira de reflorestamento, principalmente a de eucalipto. Foram entrevistadas 17 empresas do segmento de sala de jantar, 21 do segmento de cama e 6 do segmento de móveis sob encomenda. A experiência de uso da madeira de eucalipto foi constatada em $43,2 \%$ das empresas, sendo os principais fatores que influenciaram seu uso: o fato de a madeira ser proveniente de floresta plantada e ter características uniformes, além da escassez de madeira oriunda de florestas nativas. Das empresas que nunca usaram a madeira de eucalipto, $88 \%$ já ouviram falar das suas potencialidades, mas não usavam porque tinham pouco conhecimento sobre o assunto, faltavam fornecedores, não havia demanda por parte dos consumidores e consideravam alto o preço dessa madeira. Conclui-se que a maioria das empresas tinha interesse em usar a madeira de eucalipto no futuro, desde que tenha maiores informações e que o preço seja acessível.
\end{abstract}

Palavras-chave: Fabricação de móveis, madeira de eucalipto e polo moveleiro.

\section{THE PERCEPTION OF MANUFACTURERS OF THE FURNITURE CENTER OF UBÁ-MG ABOUT THE USE OF EUCALYPTUS WOOD}

\begin{abstract}
The main objective of this work was to analyze the perception of the manufacturers of the furniture center of Ubá-MG, Brazil on the use of eucalyptus wood for furniture production. The increasing environmental restraint on the use of wood from native forests has stimulated the use of reforestation plantings specially of eucalyptus. A questionnaire was made and applied to the undertakers of the furniture center of Uba, who use solid wood for furniture production, including seventeen of the dining-room section, twenty-one of the bedroom section and six of the made-to-order furniture section. The experience of using eucalyptus wood was observed in $43.2 \%$ of the enterprises. The main factors that influenced its use were: the fact that the lumber comes from planted forest and have uniform characteristics, and the scarcity of wood from native forest. $88 \%$ of the enterprises that have never used eucalyptus wood have already learned about its potentialities but do not use it because of their little knowledge about it, the lack of suppliers, lack of consumer demand and high price. It was concluded that most enterprises have interest in the use of eucalyptus wood in the future, once they obtain more information and reasonable price.
\end{abstract}

Keywords: Furniture production, eucalyptus wood and furniture center.

\section{INTRODUÇÃO}

Segundo a Abimóvel (2007), a indústria brasileira de móveis é formada por mais de 16.104 micros, pequenas e médias empresas que geram mais de 206.352 empregos.
São empresas familiares, tradicionais e, na grande maioria, de capital inteiramente nacional. O polo moveleiro de Ubá, MG, constitui o terceiro polo moveleiro do Brasil e o primeiro de Minas Gerais (PIRES et al., 2008).

\footnotetext{
${ }^{1}$ Recebido em 05-11-2007 e aceito para publicação em 23.06.2009.

${ }^{2}$ Pós-Graduação em Ciencia Florestal da Universidade Federal de Viçosa (UFV). E-mail: 〈tatianaborges@yahoo.com.br〉 e <vavpires2005@yahoo.com.br>.

${ }_{3}^{3}$ Departamento de Engenharia Florestal da Universidade Federal de Viçosa (UFV). E-mail: <marlosil@ ufv.br>e <jacovine@ufv.br>.
} 
Souza (2008) afirmou que a indústria brasileira de móveis possui grande potencial para elevar sua competitividade em relação aos demais países exportadores, sendo as razões de crescimento os recentes investimentos em novas plantas industriais, projetadas, em especial, para atender à demanda das exportações.

O setor moveleiro no Brasil tem sido marcado por um processo de utilização crescente de madeiras provenientes de florestas plantadas, principalmente a de eucalipto. Tal fato tem-se tornado mais evidente nos últimos anos, sobretudo em razão dos questionamentos existentes em relação à exploração das florestas nativas, seja por razões ecológicas, seja pela elevação dos preços, devido às dificuldades de exploração e ao distanciamento entre as zonas de produção e de consumo (ABREU et al., 2002).

No passado, a madeira de eucalipto apresentava diversos problemas para ser utilizada na indústria moveleira, como elevada retratibilidade, propensão ao colapso durante a secagem e a presença de tensões de crescimento, que provocavam rachaduras e empenamentos dos produtos acabados. Com o avanço tecnológico, esses problemas foram reduzidos, e a madeira de eucalipto, atualmente, tem sido empregada na confecção de móveis de alto padrão de qualidade. Os avanços na qualidade da madeira dessa espécie para móveis foram obtidos através de novas técnicas de desdobro, secagem e acabamento (SILVA, 2003; SERPA et al., 2003).

Apesar disso, ainda há certa resistência ao uso da madeira de eucalipto por parte dos fabricantes de móveis, em que ainda pesam conceitos ultrapassados e mitos sobre as potencialidades da madeira de eucalipto. Nesse contexto, este trabalho teve como objetivo geral analisar a percepção dos fabricantes do Polo Moveleiro de Ubá, MG, quanto à utilização da madeira de eucalipto para a fabricação de móveis.

Especificamente, objetivou-se:

- Caracterizar as empresas quanto ao porte, tempo de existência, destino da produção e público-alvo.

- Identificar a quantidade consumida de madeira maciça de essências nativas, bem como suas origens.

- Identificar a quantidade consumida de madeira de eucalipto, sua origem e preço, bem como sua utilização.

\section{MATERIAL E MÉTODOS}

Este estudo foi realizado no Pplo Moveleiro de Ubá, localizado na região sudeste do Estado de Minas Gerais. As principais cidades envolvidas no polo são: Ubá, Visconde do Rio Branco, São Geraldo, Tocantins, Piraúba, Rio Pomba, Rodeiro e Guidoval.

A fonte inicial de dados utilizada foi o conjunto de empresas (183) associadas e não associadas ao Sindicato Intermunicipal das Indústrias de Marcenaria de Ubá (INTERSIND). Pelo fato de a pesquisa ter como foco as empresas que fabricam móveis, usando madeira maciça, 45 estabelecimentos industriais foram imediatamente excluídos, por serem fabricantes de móveis tubulares, aramados, acessórios para móveis, máquinas e equipamentos. Todas as empresas desses segmentos foram contatadas previamente por telefone, e somente as usuárias foram selecionadas para a entrevista.

Foram contatados 72 estabelecimentos industriais, dos quais 53 usavam madeira maciça. Como nem todas as empresas se disponibilizaram a colaborar com a pesquisa, utilizou-se a amostragem por acessibilidade que, segundo Gil (1999), é um tipo de amostragem nãoprobabilística, em que o pesquisador seleciona os elementos a que tem acesso. Nesse caso, suposições estatísticas sobre erros de amostragem e estimativas dos parâmetros da população não se aplicam ao referido estudo.

A caracterização quanto à resistência e qualidade da madeira de eucalipto para a fabricação de móveis foi realizada pelos entrevistados, tendo como opções a qualidade ótima, boa ou ruim.

Por conseguinte, a amostragem (Figura 1) foi constituída pelas 44 empresas que se dispuseram a responder ao questionário de pesquisa.

O instrumento de coleta de dados utilizado foi o questionário, elaborado sob dois tipos, sendo um para as empresas que usam a madeira de eucalipto e outro para as que não usam, visando identificar a empresa, o consumo de madeira maciça, sua origem e preço; diagnosticando o uso da madeira de eucalipto; e a percepção dos fabricantes em relação a essa espécie. Esses questionários foram aplicados nos meses de março a abril de 2005.

Posteriormente, os dados foram codificados, a fim de facilitar o processo de contagem e agrupamento das informações em planilha eletrônica. Utilizou-se a 


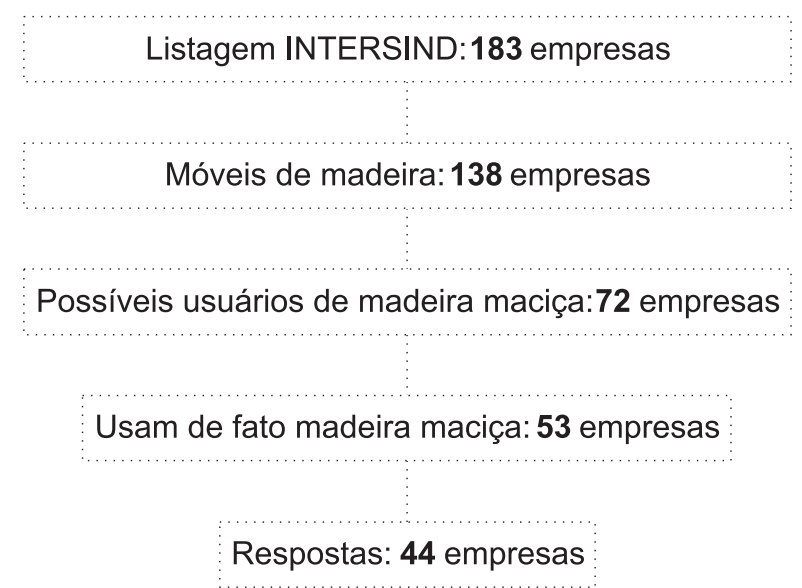

Figura 1 - Esquema de delimitação da população e da amostra de pesquisa.

Figure 1-Delimitation design of the population and research sample.

tabulação cruzada, que consiste na contagem das freqüências, simultaneamente, em dois ou mais conjuntos de categorias.

\section{RESULTADOS E DISCUSSÃO}

\subsection{Aspectos gerais das empresas}

De acordo com o número de funcionários, as indústrias de móveis dos segmentos estudados variam de micro a médias empresas, havendo forte predomínio $(72,7 \%)$ de estabelecimentos de microporte com até 19 empregados. As pequenas empresas, com 20 a 99 funcionários, correspondem a $22,7 \%$ do total pesquisado, e apenas $4,6 \%$ são de porte médio.

Mais da metade das empresas entrevistadas (52,3\%) foi aberta há menos de 10 anos, em que 52,9\% das empresas do segmento de sala de jantar foram fundadas após o ano de 1994, assim como $61,9 \%$ do segmento de camas. Observou-se que $34,1 \%$ dos estabelecimentos pesquisados já estavam no mercado entre 10 e 20 anos e 13,6\% há mais de 20 anos.

A produção de móveis possui destino inter-regional. O Estado de Minas Gerais concretiza-se como principal receptor dos produtos fabricados, e parcela considerada das indústrias $(47,7 \%)$ indicam o Estado do Rio de Janeiro como grande comprador de móveis da região de Ubá. Destacam-se ainda os Estados do Espírito Santo (34,1\%), Bahia (29,5\%) e São Paulo (20,5\%). A Região Nordeste foi citada como um dos mercados consumidores em expansão.

A atividade de exportação é praticada pela minoria das empresas entrevistadas, sendo $11,8 \%$ do segmento sala de jantar e $4,8 \%$ do segmento cama. Os produtos têm como principais destinos os países da África do Sul, Chile, México e Estados Unidos.

O público-alvo da maioria $(70 \%)$ das empresas sob análise são os consumidores da classe média, principalmente o segmento de salas de jantar (94\%). Cerca de $57 \%$ dos fabricantes de cama têm como destino para seu produto clientes da classe baixa, pois a maioria vende camas "populares", de baixo valor agregado. Observou-se que as empresas de móveis sob encomenda têm como foco os consumidores de poder aquisitivo maior, das classes média e alta, fato que pode ser justificado pela alta especialização do produto.

\subsection{Consumo de madeira maciça}

Através de dados secundários e junto a profissionais do setor, foi constatado que, entre os segmentos do Polo Moveleiro de Ubá predominam como usuários de madeira maciça: salas de jantar, camas e móveis sob encomenda.

Nem todos os fabricantes desses segmentos usam madeira maciça, uma vez que os móveis podem também ser fabricados com chapas de madeira processada

O consumo total de madeira maciça das empresas entrevistadas era da ordem de $987,5 \mathrm{~m}^{3}$ por mês. Percebeu-se que o maior consumo de madeira maciça está no segmento de sala de jantar, com $51,7 \%$ do total, embora o número de empresas de camas seja maior.

Como pode ser observado na Figura 2, de todas as empresas entrevistadas, $59,1 \%$ consomem menos de $20 \mathrm{~m}^{3}$ de madeira maciça por mês, o que é condizente com o tamanho desses estabelecimentos, que são, na maioria, de micro porte. As pequenas marcenarias, que compõem o segmento de móveis sob medida, não ultrapassam a marca dos $20 \mathrm{~m}^{3}$ mensais, e o segmento de sala de jantar é o único que tem empresas que consomem mais de $60 \mathrm{~m}^{3}$ por mês, representado por $11,8 \%$ do seu total.

R. Árvore, Viçosa-MG, v.33, n.5, p.969-975, 2009 


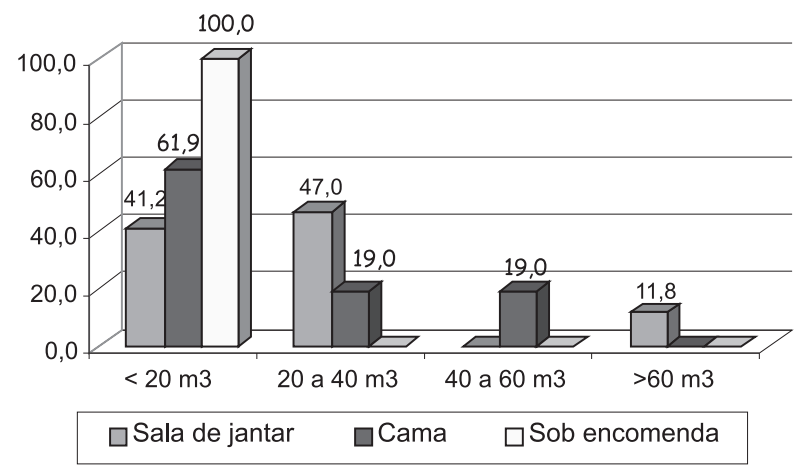

Figura 2 - Faixa de consumo de madeira maciça ( $\left.\mathrm{m}^{3} / \mathrm{mês}\right)$, por segmento.

Figure 2-Range of consumption of solid wood $\left(\mathrm{m}^{3} / \mathrm{month}\right)$ per segment.

A predominância da madeira de floresta nativa $(83,2 \%)$ é constatada em todos os segmentos pesquisados, principalmente o de cama, em que $98 \%$ das madeiras consumidas são oriundas de florestas nativas (Figura 3). No entanto, as empresas de sala de jantar apresentam o maior percentual $(30,5 \%)$ de uso de madeira de floresta plantada, principalmente o eucalipto.

As essências nativas mais consumidas, de acordo com os entrevistados, são: imbirema (Couratari oblongifolia Ducke \& R. Knuth) ou tauari (Couratari guianensis Aubl.) (32,6\%), sucupira (Bowdichia virgilioides H. B. K.) $(16,1 \%)$ e angico (Anadenabthera peregrina (L.) Speg.) (10,2\%) (ressalta-se que não foram feitas caracterizações anatômicas para identificação das espécies). Em relação à madeira de reflorestamento, o consumo de eucalipto (Eucalyptus sp.) foi a terceira essência mais consumida, representando $16 \%$ do total.

As madeiras de espécies nativas consumidas são compradas, principalmente, dos Estados do Pará (56,8\%), Rondônia (38,6\%) e Minas Gerais (25\%), sendo este último responsável por $83,3 \%$ das madeiras consumidas pelo segmento de móveis sob encomenda. Essas empresas têm baixa capacidade de investimento e poder de barganha com os fornecedores, uma vez que seu volume de compras é pequeno, fazendo que grande parte da madeira comprada na cidade de Ubá ou na sua região, através de distribuidores.

R. Árvore, Viçosa-MG, v.33, n.5, p.969-975, 2009

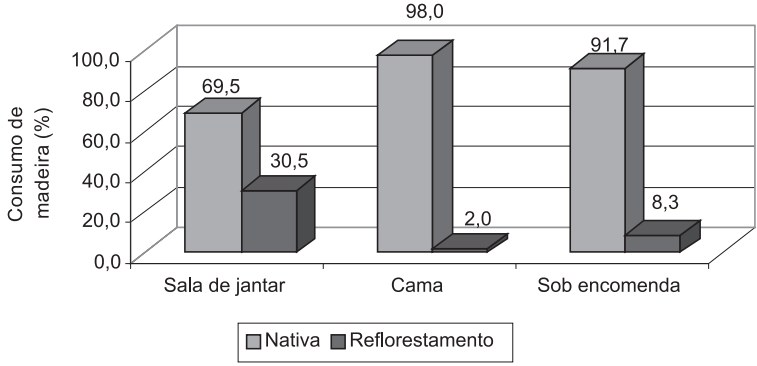

Figura 3-Origem das essências florestais consumidas, por segmento.

Figure 3-Origin of the consumed forest essences, per segment.

\subsection{O uso da madeira de eucalipto}

Das 44 empresas entrevistadas, $19(43,2 \%)$ tem alguma experiência com a madeira de eucalipto para a fabricação de móveis. Os fabricantes de sala de jantar destacam-se pelo maior número de estabelecimentos com experiência (13). A maior parte do segmento de cama (16) nunca fez uso dessa espécie, e apenas uma empresa de móveis sob encomenda declarou usar a madeira de eucalipto (Figura 4).

Das empresas que usam a madeira de eucalipto, observou-se que 31,6\% usam-na há menos de 2 anos, $47,3 \%$ de 2 a 5 anos e $21,1 \%$ há mais de cinco anos.

Atualmente, são consumidos $158 \mathrm{~m}^{3}$ de madeira de eucalipto por mês (Tabela 1) pelas empresas pesquisadas, sendo o segmento de sala de jantar responsável por $94,0 \%$ desse consumo.

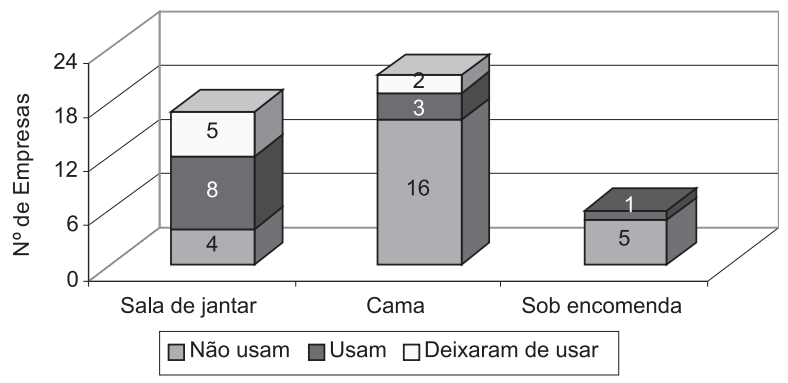

Figura 4-Número de empresas que não usam, usam ou já usaram a madeira de eucalipto.

Figure 4-Number of companies which do not use, use or have already used eucalyptus wood. 
Tabela 1 - Consumo da madeira de eucalipto ( $\left.\mathrm{m}^{3} / \mathrm{mês}\right)$. Table 1 - Consumption of eucalyptus wood ( $\left.\mathrm{m}^{3} / \mathrm{month}^{2}\right)$.

\begin{tabular}{|c|c|c|c|c|c|}
\hline \multirow[t]{2}{*}{ Empresa } & \multicolumn{3}{|c|}{ Segmento } & \multirow[t]{2}{*}{ Total } & \multirow[t]{2}{*}{$\%$} \\
\hline & Sala de jantar & Cama & $\begin{array}{c}\text { Sob } \\
\text { encomenda }\end{array}$ & & \\
\hline Usam atualmente & 148,5 & 8,0 & 1,5 & 158,0 & 39,6 \\
\hline Deixaram de usar & 181,0 & 60,0 & - & 241,0 & 60,4 \\
\hline Total & 329,5 & 60,8 & 1,5 & 399,0 & 100,0 \\
\hline
\end{tabular}

Das 19 empresas que afirmaram ter experiência com a madeira de eucalipto, $36,8 \%$, atualmente, não estão usando essa espécie (Figura 3). Em termos de volume, isso significa que $241 \mathrm{~m}^{3}$ mensais deixaram de ser consumidos (Tabela 1). As empresas que deixaram de usar o eucalipto, embora sejam a minoria, eram responsáveis pelo maior consumo. Os principais motivos citados foram: a elevação do preço da madeira $(57,1 \%)$; problemas técnicos, como empenamentos e rachaduras (42,9\%); e o abastecimento precário do fornecedor $(28,6 \%)$.

A madeira de eucalipto consumida pelas empresas entrevistadas tem origem, principalmente, no Estado da Bahia, onde está localizada a empresa ARACRUZ, que produz o Lyptus, madeira de eucalipto produzida especialmente para a fabricação de móveis. Algumas empresas $(15,8 \%)$ também compram a madeira de eucalipto de serrarias da região de Ubá e Espírito Santo.

Em relação ao preço da madeira de eucalipto comprada (Figura 5), observou-se que as empresas que compram o Lyptus da ARACRUZ pagam mais caro pela madeira, o que é justificado pela sua alta qualidade. A maior parte dessas empresas $(36,8 \%)$ paga em torno de $\mathrm{R} \$ 600,00$ a $\mathrm{R} \$ 700,00$ por $\mathrm{m}^{3}$. Os preços dessa empresa variam porque a madeira é comercializada em quatro classes, com padrões de qualidade e preços diferenciados. Já as empresas que compram de serrarias dos Estados de Minas Gerais e Espírito Santo pagam em torno de $\mathrm{R} \$ 300,00$ a $\mathrm{R} \$ 500,00$ por $\mathrm{m}^{3}$. A diferença de preço se dá, principalmente, pelo fato de essa madeira não ser adquirida seca.

No geral, a maior parte das empresas (53\%) considera razoável o preço da madeira, $42 \%$ acredita que o preço está alto, tornando muitas vezes inviável sua utilização, pois os produtos ficam pouco competitivos no mercado. Apenas 5\% das empresas consideram o preço baixo.

\subsection{A percepção dos fabricantes que usam a madeira de eucalipto}

A principal fonte de informação citada pelas empresas, sobre o uso da madeira de eucalipto para a fabricação de móveis, foram os representantes comerciais $(57,9 \%)$ e visitas a feiras e exposições $(36,8 \%)$. O fato de os segmentos analisados constituírem-se, em sua maioria, de empresas de micro e pequeno portes, caracterizadas por restrita capacidade tecnológica e financeira, limita a utilização da madeira de eucalipto, uma vez que esses estabelecimentos avançam muito pouco em relação à busca de novos materiais e equipamentos.

Os fabricantes de móveis relatam que a madeira de eucalipto atende às suas necessidades $(57,9 \%)$ no que se refere à sua trabalhabilidade e 52,6\% no que se refere à colagem.

Os móveis fabricados com madeira de eucalipto pelas empresas entrevistadas, em sua maioria $(63,2 \%)$, as formas e contornos trabalhados nos móveis, a tinta se torna essencial ao visual dos produtos acabados. De acordo com o depoimento de alguns fabricantes, muitas vezes o cliente compra o móvel nas lojas sem saber que foi feito de eucalipto, pelo

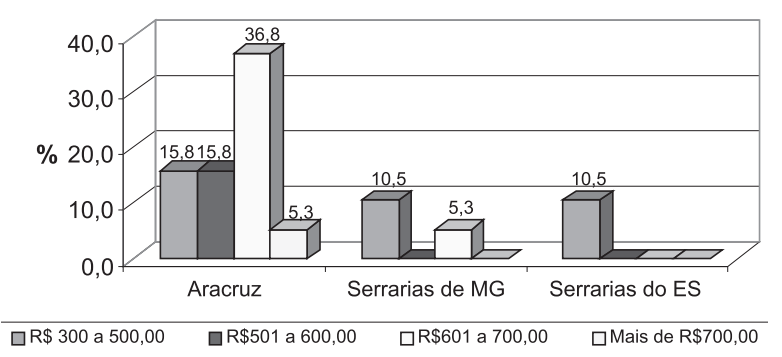

Figura 5-Faixa de preço da madeira de eucalipto consumida. Figure 5-Band of price of the wood of eucalyptus consumed.

R. Árvore, Viçosa-MG, v.33, n.5, p.969-975, 2009 
fato de serem tingidos nos diversos padrões encontrados no mercado, como o mogno, marfim e tabaco.

No geral, 52,6\% das empresas que têm experiência com a madeira de eucalipto a consideram ótima para a fabricação de móveis e $47,4 \%$ a consideram boa.

Os empresários citaram como principais fatores que influenciam o uso dessa espécie na fabricação de seus produtos o fato de a madeira ser proveniente de floresta plantada $(94,7 \%)$; ter características uniformes, o que é importante na fabricação de móveis (84,2\%); e a falta de madeira nativa, cada vez mais escassa $(63,2 \%)$. A demanda por parte do consumidor aparece de forma não muito expressiva, sendo possível perceber o incipiente interesse das pessoas por móveis "ecologicamente corretos", talvez pela falta de informações sobre a real qualidade dessa madeira.

A maior parte dos fabricantes de móveis $(68,4 \%)$ afirmou que nunca teve problemas com a madeira de eucalipto, no entanto, 31,6\% disseram o contrário e apontaram, principalmente, problemas relacionados a empenamentos, rachaduras, nós e falta de uniformidade da madeira. Desses empresários, 33,3\% admitiram que os problemas foram decorrentes de manuseio incorreto, como a utilização de madeira verde. Os demais julgaram que os problemas estão relacionados diretamente com as características intrínsecas da madeira.

\subsection{A percepção dos fabricantes que não usam a madeira de eucalipto}

Do total de empresas entrevistadas que não usam a madeira de eucalipto, $56,8 \%$ nunca usou essa espécie; no entanto, pelo menos $88 \%$ delas já ouviu falar de suas potencialidades para a fabricação de móveis. As principais fontes de informação foram os representantes comerciais $(52,0 \%)$ e visitas a feiras e exposições $(44,0 \%)$. Alguns fabricantes $(8,0 \%)$ já tiveram a oportunidade de trabalhar com o eucalipto em outras fábricas, onde eram empregados. Apenas 4,0\% citaram revistas especializadas no setor moveleiro como fonte de informação.

Cerca de $68 \%$ dos empresários que nunca usaram a madeira de eucalipto já tiveram a oportunidade de ver um móvel feito com essa espécie, e 76,5\% acharam a aparência boa, 70,6\% consideraram a resistência e a qualidade aparentemente boas da madeira. No entanto, $5,9 \%$ acharam ruim a resistência e a aparência dessa espécie nos móveis acabados.

R. Árvore, Viçosa-MG, v.33, n.5, p.969-975, 2009
A pesquisa revelou que a maior parte $(56,0 \%)$ dos fabricantes de móveis não usa a madeira de eucalipto no processo produtivo, porque não tem informações sobre o assunto. Apesar de já terem ouvido falar das potencialidades dessa madeira, falta-lhes um conhecimento mais aprofundado em relação à espécie mais adequada, à forma de secagem e à correta usinagem do eucalipto.

A irregularidade de oferta dessa madeira no mercado também é um impedimento para 52,0\% dos entrevistados, que se queixam da falta de fornecedores. A demanda por parte dos consumidores, para 44,0\% das empresas, ainda é um fator limitante, uma vez que, ainda, há pouca procura por móveis de madeira de eucalipto.

Em relação ao abastecimento de madeira, observou-se que a maioria das empresas $(52,0 \%)$ nunca teve problemas dessa natureza, e $48,0 \%$ já tiveram conflitos no processo produtivo decorrentes da falta de madeira ou do seu atraso na entrega, bem como do aumento do preço, ocasionando elevação nos custos de produção.

Observou-se que a falta de conhecimento sobre o assunto leva alguns empresários a manter velhos conceitos e mitos sobre a madeira, o que faz $20,0 \%$ dos empresários acreditarem que a madeira de eucalipto não seja apropriada para a fabricação de móveis.

Contribuindo para identificar a preocupação dessas empresas com o meio ambiente, questionou-se a importância da madeira de eucalipto para a preservação ambiental. Como era de se esperar, as empresas responderam, com unanimidade, que, apesar de não usarem a madeira de eucalipto, preocupavam-se com as questões ambientais.

Ao serem questionadas sobre a certificação florestal, ou seja, se tinham algum conhecimento sobre o assunto ou se compravam madeira certificada, a maior parte $(72,0 \%)$ não teve nenhuma informação sobre esse assunto. Embora $24,0 \%$ tenham respondido que compravam madeira certificada, observou-se durante a entrevista que essas empresas não tinham tanto conhecimento sobre o assunto quanto afirmaram. Na verdade, elas confundem a madeira certificada com a madeira legalizada, pois, quando compram a mercadoria, a nota fiscal chega com vários carimbos de fiscalização, bem como guias de liberação e tributação dos órgão competentes, 
como o IEF. Ou seja, esses $24,0 \%$ são considerados irreais, podendo-se afirmar que apenas uma das empresas tinha informações reais sobre a certificação, bem como comprava madeira certificada.

Apesar da grande falta de informações sobre o uso da madeira de eucalipto, a pesquisa revelou que $84,0 \%$ dos estabelecimentos entrevistados tiveram interesse de usar essa espécie futuramente.

Segundo os fabricantes, seria necessário que tivessem mais informações sobre o assunto (52,0\%), que o preço fosse razoável $(40,0 \%)$ e que houvesse mais fornecedores da madeira de eucalipto de qualidade no mercado $(40,0 \%)$.

A demanda do consumidor influenciaria de forma menos relevante. Isso pode ser justificado pelo fato de os móveis serem tingidos em diversos padrões de madeira. Na verdade, muitas vezes, o consumidor final não sabe com qual madeira o móvel foi fabricado.

\section{CONCLUSÃO}

Com este trabalho foi possível concluir que:

- O uso de madeira de reflorestamento ainda é incipiente nas fábricas pesquisadas.

- A estrutura da indústria impõe limites à modernização e busca de novos materiais, devido à restrição de recursos.

- O acúmulo de funções do dono da micro e pequena empresa limita seu tempo e impede que ele busque inovações tecnológicas.

- As informações chegam até esses empresários, por meio dos representantes comerciais, que se tornam a principal fonte de informação sobre novos materiais e equipamentos.

- Ocorre falta de informação sobre a madeira de eucalipto. A dificuldade de acesso a essa matéria-prima e aos métodos adequados de manuseá-la dificulta a sua utilização nas empresas estudadas.

- Poucas empresas detêm a oferta de madeira serrada de boa qualidade, e o valor de comercialização é considerado ainda alto para o mercado interno ampliar seu uso. A tecnologia adequada para trabalhar essa madeira ainda não está bem difundida entre os fabricantes.
- Existe oportunidade para a indústria moveleira com relação à produção de móveis de madeira certificada de reflorestamento.

\section{AGRADECIMENTOS}

Ao CNPq, pelo apoio financeiro e pela concessão de bolsas; À CAPES, pela concessão de bolsa;. À Fapemig, pelo apoio financeiro; e à UFV, pela infraestrutura e pessoal disponibilizados para a realização deste trabalho.

\section{REFERÊNCIA}

\section{ABIMÓVEL. Panorama do setor} moveleiro no Brasil: informações gerais. São Paulo, 2007. v.2. Disponível em: <http:// www.abimovel.com/download/ Panorama\%20Agosto\%202006\%20\%20Reduzido.doc>. Acesso em: 12 fev. de 2009.

ABREU, L. C. M. et al. Diagnóstico de consumo e suprimento de produtos madeireiros no setor moveleiro do Município de Ubá-MG. Revista Árvore, v.26, n.2, p.155-164, 2002.

\section{GIL, A. C. Métodos e técnicas de} pesquisa social. São Paulo: Atlas, 1999. 208p.

PIRES, V. A. V. et al. Viabilidade econômica de implantação da central de gerenciamento de resíduos no polo moveleiro de Ubá, MG.

Revista Cerne, v.14, n.4, p.295-303, 2008.

SERPA, P. N. et al. Avaliação de algumas propriedades da madeira de Eucalyptus gradis, Eucalyptus saligna e Pinus elliottii. Revista Árvore, v.27, n.5, p.723-733, 2003.

SILVA, J. C. Por que usar eucalipto? Revista da Madeira, v.13, n.75, p.7-10, 2003.

SOUZA, C. C. Avaliação de impactos ambientais da atividade industrial no pólo moveleiro de Ubá - MG. 2008. 177f. Dissertação (Mestrado em Ciência Florestal) - Universidade Federal de Viçosa, Viçosa, MG, 2008. 
